\title{
Correction to: Laparoscopic Duodenojejunostomy for Superior Mesenteric Artery Syndrome
}

\author{
Gregory A. Magee ${ }^{1} \cdot$ Bethany J. Slater $^{1} \cdot$ Jason T. Lee ${ }^{1} \cdot$ George A. Poultsides $^{1}$
}

Published online: 4 February 2021

๑) Springer Science+Business Media, LLC, part of Springer Nature 2021

\section{Correction to: \\ Digestive Diseases and Sciences 56:2528-2531 \\ https://doi.org/10.1007/s10620-011-1757-0}

The original version of the article unfortunately contained an error in one of the authors name in the author group. The first author name was published as 'Gregory Magee' and the corrected name is 'Gregory A. Magee'.

Publisher's Note Springer Nature remains neutral with regard to jurisdictional claims in published maps and institutional affiliations.

The original article can be found online at https://doi.org/10.1007/ s10620-011-1757-0.

George A. Poultsides

gpoultsides@stanford.edu

1 Department of Surgery, Stanford University Medical Center, Stanford, CA, USA 